\title{
Influence of biological origin on the tensile properties of cellulose nanopapers
}

\author{
Katri S. Kontturi · Koon-Yang Lee $\cdot$ Mitchell P. Jones • William W. Sampson • \\ Alexander Bismarck • Eero Kontturi $(\mathbb{C}$
}

Received: 11 February 2021 / Accepted: 9 May 2021 / Published online: 22 May 2021

(C) The Author(s) 2021

\begin{abstract}
Cellulose nanopapers provide diverse, strong and lightweight templates prepared entirely from sustainable raw materials, cellulose nanofibers (CNFs). Yet the strength of CNFs has not been fully capitalized in the resulting nanopapers and the relative influence of CNF strength, their bonding, and biological origin to nanopaper strength are unknown. Here, we show that basic principles from paper physics can be applied to CNF nanopapers to illuminate those relationships. Importantly, it appeared that $\sim 200$ MPa was the theoretical maximum for nanopapers with random fibril orientation. Furthermore, we
\end{abstract}

Supplementary Information The online version contains supplementary material available at https://doi.org/10.1007/ s10570-021-03935-2.

\section{K. S. Kontturi}

Department of Chemical Engineering, Imperial College London, South Kensington Campus, London SW7 2AZ, UK

\section{K. S. Kontturi}

Functional Cellulose, VTT Technical Research Centre of Finland Ltd, 02150 Espoo, Finland

\section{K.-Y. Lee}

Department of Aeronautics, Imperial College London, South Kensington Campus, London SW7 2AZ, UK

\section{K.-Y. Lee}

Institute for Molecular Science and Engineering, Imperial College London, South Kensington Campus,

London SW7 2AZ, UK demonstrate the contrast in tensile strength for nanopapers prepared from bacterial cellulose (BC) and wood-based nanofibrillated cellulose (NFC). Endemic amorphous polysaccharides (hemicelluloses) in NFC act as matrix in NFC nanopapers, strengthening the bonding between CNFs just like it improves the bonding between CNFs in the primary cell wall of plants. The conclusions apply to all composites containing non-woven fiber mats as reinforcement.

M. P. Jones · A. Bismarck $(\bowtie)$ Institute of Materials Chemistry, University of Vienna, Währinger Strasse 42, 1090 Vienna, Austria e-mail: alexander.bismarck@univie.ac.at

\section{P. Jones}

Institute of Materials Science and Technology, Faculty of Mechanical and Industrial Engineering, TU Wien, Getreidemarkt 9, 1060 Vienna, Austria

W. W. Sampson $(\square)$

Department of Materials, University of Manchester, Manchester M13 9PL, UK

e-mail: william.sampson@manchester.ac.uk

E. Kontturi $(\bowtie)$

Department of Bioproducts and Biosystems, Aalto University, P.O. Box 16300, 00076 Aalto, Finland e-mail: eero.kontturi@aalto.fi 


\section{Graphic abstract}

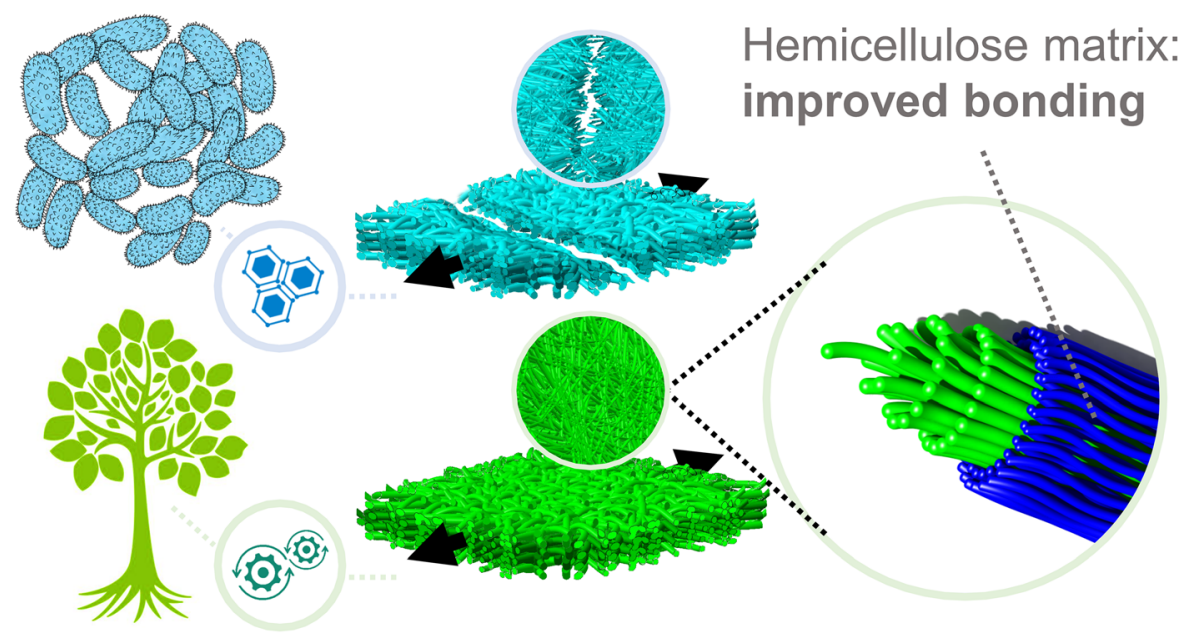

Keywords Bacterial cellulose $\cdot$ Cellulose nanofibers $\cdot$ Hemicellulose $\cdot$ Random networks . Tensile stiffness $\cdot$ Tensile strength

\section{Introduction}

Fibrillar networks, particularly those built of nanoscale fibers, are the route forward for the development of new membranes and composites, as well as a host of high-end applications, including sensors, optically responsive templates, and flexible electronics.(Sun et al. 2018; Wang et al. 2019a; Yang et al. 2020a; Zeng et al. 2020) Recently, as a result of advanced fibrillation techniques, cellulose nanofibers (CNFs) have emerged as an alternative material for network preparation into so-called cellulose nanopapers.(Barhoum et al. 2017; Dai et al. 2018; Fang et al. 2014; Henriksson et al. 2008; Toivonen et al. 2018; Yang et al. 2020b; Zhu et al. 2015) CNFs are attractive since they are renewable, lightweight yet very strong, and can be extracted from sustainable raw materials.(Kontturi et al. 2018) Unlike regular paper, nanopapers can also be optically transparent because of the small size of the CNFs and high density.(Fang et al. 2014) Although the strength of an individual CNF is extremely high (allegedly 2-6 GPa),(Saito et al. 2013) their potential has not been fully capitalized in nanopapers.(Barhoum et al. 2017) Inevitably, the relatively low network strength is a consequence of its structure and the quality of adhesion between the CNFs but the relative influence of these is unknown.(Barhoum et al. 2017; Zhu et al. 2015) Here, we attempt to tackle the relative contributions to nanopaper strength by applying existing theories for fibrillar networks on a concise dataset.

In order to experimentally address the issue of nanopaper strength, we have utilized two CNFs from manifestly different biological origins: bacterial cellulose (BC) and wood-based nanofibrillated cellulose (NFC). BC is chemically pure grade of cellulose produced bottom-up from sugars as a 3D network of individual CNFs by cellulose-producing bacteria (Fig. 1a) and it consists solely of cellulose.(Wang et al. 2019b) NFC, on the other hand, is prepared topdown by high pressure mechanical disintegration of plant fiber cell wall, usually from processed wood (Fig. 1b).(Nechyporchuk et al. 2016) Both grades consist essentially of semi-crystalline cellulose fibrils but NFC contains an integral amount of other woodbased, amorphous polysaccharides (hemicelluloses). In order to emphasize the interfacial differences between the CNFs of different origins, we have utilized NFC with exceptionally high $(27 \%)$ hemicellulose content as a counterpart to the chemically pure BC. The effect of hemicelluloses as an adhesive component in nanopapers is known (Iwamoto et al. 2008; Nobuta et al. 2016) but it has never been theoretically addressed. Intriguingly, hemicelluloses play a large part in the mechanical integrity of the primary cell wall of plants (Fig. 1c). Exhibiting an 

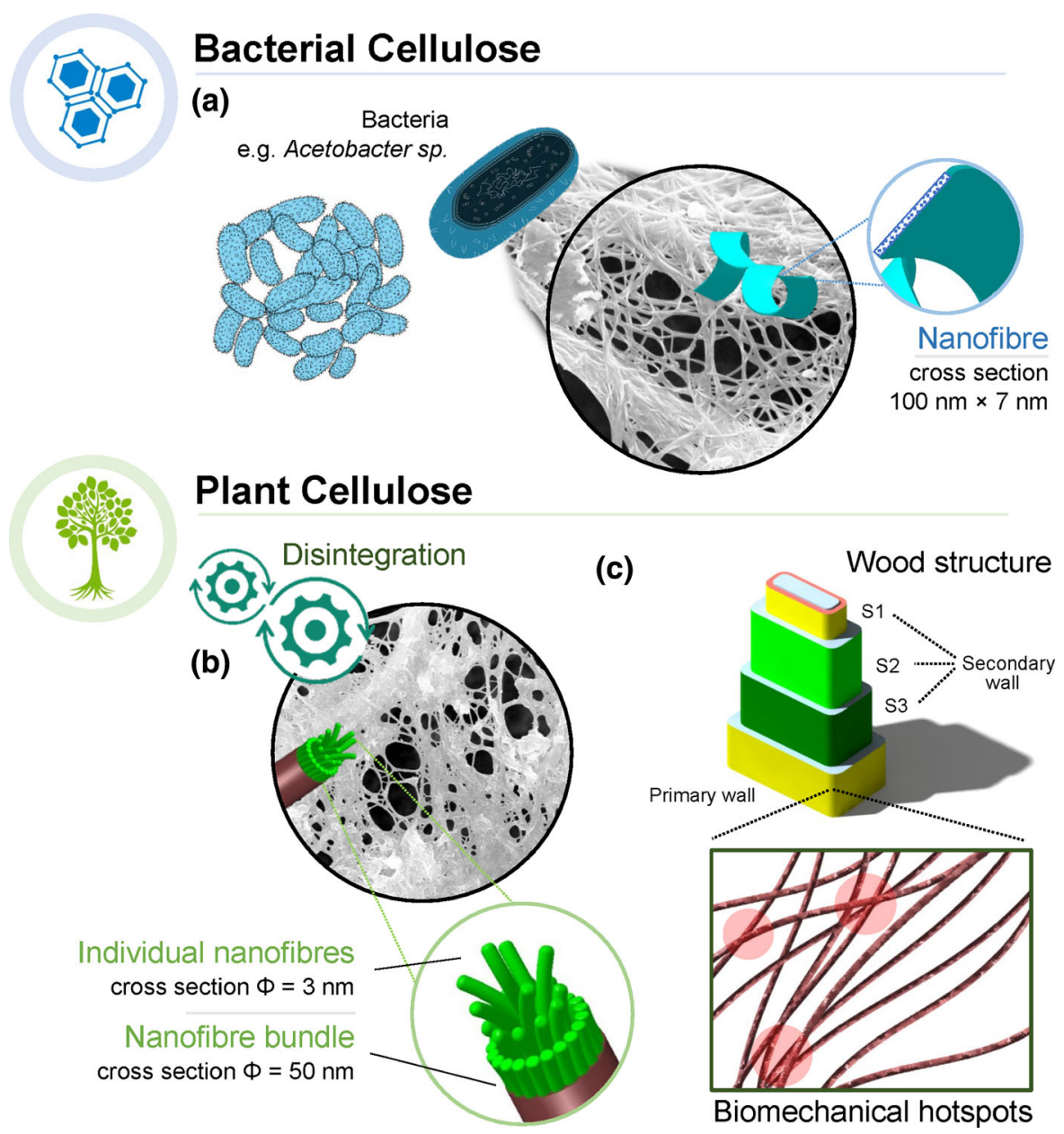

Fig. 1 a Extrusion of a network of bacterial cellulose nanofibrils with associated (nano)fibril cross-sectional morphology. b Mechanical disintegration of plant matter to produce NFC with associated cross-sectional morphology that corresponds to a bundle of individual cellulose microfibrils. Cellulose

isotropic network of microfibrils, primary wall is significantly strengthened by "biomechanical hotspots" where coiled hemicelluloses are acting as a matrix in the microfibril junctions (Fig. 1c).(Cosgrove 2014; Zhang et al. 2016) The primary wall is subject to significant mechanical stress as it must resist the turgor (osmotic) pressure while extending during cell growth.(Cosgrove 2014) Because NFC is essentially made by isolating microfibrils from the cell wall, this allows us to draw a parallel between the strengthening effect of hemicelluloses in the primary cell wall and in CNF nanopapers. We stress that we use the term microfibril to denote the smallest supramolecular unit of cellulose in plants, in line with the current microfibrils are present in the cell wall of wood, along with hemicelluloses, protein and lignin. Biomechanical hotspots occur at junctions between two or more microfibrils, or upon close cellulose-cellulose contact, mediated by matrix polysaccharides, such as coiled xyloglucan

nomenclature.(Jarvis 2018) When isolated from plants, NFC generally consists of bundles of microfibrils.

\section{Experimental}

\section{Materials}

Bacterial cellulose (BC) was supplied by fzmb GmbH (Bad Langensalza, Germany) in wet pellicle form containing 94 wt.-\% water. Wood-based nanofibrillated cellulose, termed herein NFC, was prepared by the mechanical grinding (MKZA10-15 J 
Supermasscolloider, Masuko Sangyo Co., Kawaguchi, Japan) of chlorine-free never-dried bleached birch kraft pulp (UPM-Kymmene Corporation, Pietarsaari, Finland).(Lee et al. 2012) The pulp was passed through the grinder seven times and the final consistency of the aqueous gel-like NFC was $1.8 \mathrm{wt} \%$. The carbohydrate composition of the NFC is $73 \%$ glucose, $26 \%$ xylose, and $1 \%$ mannose, respectively. Details on the characterization are described in reference (Eronen et al. 2011).

Manufacturing of nanopapers

Nanopapers were prepared by filtration from diluted aqueous suspension of cellulose nanofibers (CNF) from either BC or NFC.

The homogeneous BC suspension of 0.1 wt.- $\%$ concentration was prepared by cutting the $\mathrm{BC}$ pellicles into small pieces (with a length of approximately $5 \mathrm{~mm}$ ) and blended (Breville VBL065/01, Oldham, UK) in deionised water for $2 \mathrm{~min}$. The NFC-suspension, on the other hand, was prepared by diluting the aqueous gel-like NFC into 0.3 wt.\% concentration with deionised water, and blending the mixture for 2 min.

For both BC-based and NFC-based nanopapers, a pre-determined amount of the suspension (the amount depending on the desired nanopaper grammage) was vacuum-filtrated onto a cellulose filter paper (VWR $413,5-13 \mu \mathrm{m}$ pore size, Lutterworth, UK) using a funnel with a glass frit (Schott, porosity No. 1, Mainz, Germany). After filtration, the wet filter cake was detached from the filter paper and sandwiched between blotting papers (Whatman 3MM Chr, VWR, Lutterworth, UK) and wet-pressed under a weight of $10 \mathrm{~kg}$ for $10 \mathrm{~min}$ to absorb the excess water. After this, the wet filter cakes were dried and consolidated in a hot-press (25-12-2H, Carver Inc., Wabash, USA) under a compression weight of $1 \mathrm{t}$ for $4 \mathrm{~h}$ at $120^{\circ} \mathrm{C}$, sandwiched between fresh blotting papers and metal plates.

\section{Characterization of nanopapers}

\section{Morphology}

Morphology of the nanopapers was characterized using scanning electron microscopy (SEM). SEM was performed using a high-resolution field emission gun
SEM (LEO Gemini 1525 FEG-SEM, Leo Electron Microscopy Ltd., Cambridge, UK) at an acceleration voltage of $5 \mathrm{kV}$. Prior to SEM, the samples were attached onto carbon tabs stuck on the SEM stub and coated with $\mathrm{Cr}$ (K550 sputter coater, Emitech Ltd., Ashford, Kent, UK) for $2 \mathrm{~min}$ at $20 \mathrm{~mA}$.

Grammage, thickness, and density

The grammage of nanopapers was determined as the ratio between the weight and planar area of the nanopapers. The thickness of a paper was determined from epoxy resin impregnated cross-sectional samples by using an optical microscope. The presented thickness values are an average of at least four parallel measurements taken from each nanopaper.

Tensile properties

Tensile deformation behavior of the nanopapers was studied by two different methods: conventional tensile testing and with zero-span test typically used in paper testing.

For tensile testing the nanopapers were cut into dog bone shape specimens using a Zwick ZCP 020 manual cutting press. The test specimen possesses an overall length of $35 \mathrm{~mm}$ and the narrowest part of the specimen is $2 \mathrm{~mm}$. Prior to the test, the specimens were secured onto testing cards using cyanoacrylatebased adhesive (Everbuild Stick 2 superglue), in order to prevent the clamp of the tensile testing equipment from damaging the test specimens. Tensile tests were conducted using a Deben MICROTEST tensile stage (Deben UK Ltd., Suffolk, UK), using a load cell of $200 \mathrm{~N}$ and crosshead speed of $0.5 \mathrm{~mm} \mathrm{~min}^{-1}$. A total of eight specimens were tested and averaged for each type of sample. Dry zero-span tensile strengths were determined according to the standard ISO 15,361:2000.

\section{Results and discussion}

The scheme of nanopaper preparation by vacuum filtration is presented in Fig. 2a, together with representative scanning electron microscope (SEM) images of the nanopaper surfaces. It is obvious that the CNFs and their bundles are more conspicuous on the $\mathrm{BC}$ nanopaper because amorphous hemicelluloses 
(a)

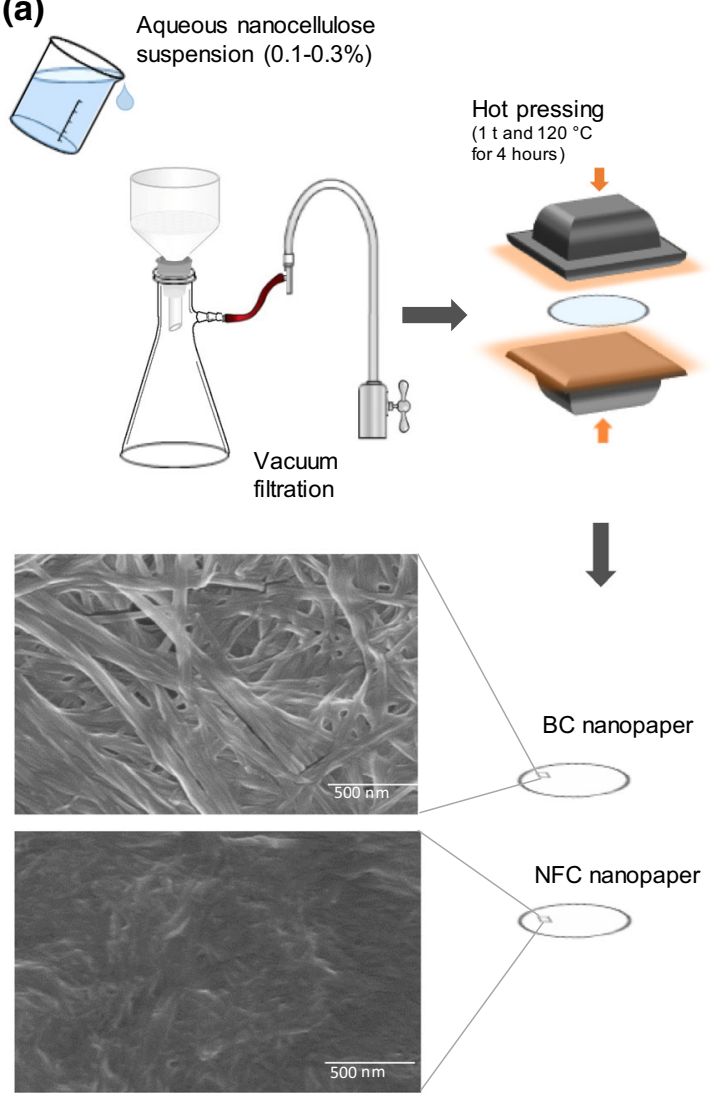

(b)

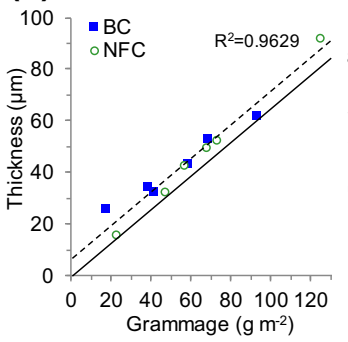

(c)

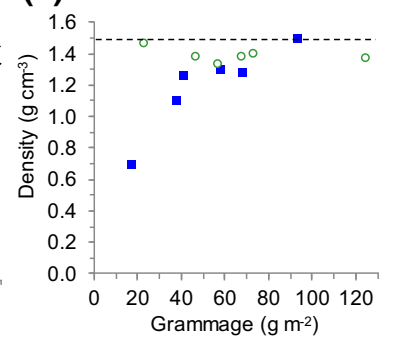

Fig. 2 a Nanopaper preparation process comprising suspension (0.1-0.3\%), vacuum filtration and hot pressing $\left(1 \mathrm{t}\right.$ at $120{ }^{\circ} \mathrm{C}$ for $4 \mathrm{~h}$ ) of nanocellulose. SEM micrographs detail the surface morphologies of bacterial- (BC) and plant-derived nanofibrillated (NFC) cellulose nanopapers. b Nanopaper thickness $(\mu \mathrm{m})$ and $\mathbf{c}$ apparent density $\left(\mathrm{g} \mathrm{cm}^{-3}\right)$ with respect to grammage $(\mathrm{g}$ $\mathrm{m}^{-2}$ )

partially bury the CNFs on the NFC nanopaper, which we observe to be qualitatively smoother.

Figure $2 \mathrm{~b}$ shows the thickness development of the cellulose nanopapers as a function of grammage [ $g$ $\mathrm{m}^{-2}$ ] - a simple but crucial property. As shown previously,(Mautner et al. 2015) the paper thickness exhibits a linear relationship against grammage with a small positive intercept arising from the non-uniformity of the networks and its rough surface. The linear relationship enables the calculation of the intrinsic density of the nanopapers by linear regression on the combined datasets (broken line in Fig. 2b): (Bloch et al. 2019) $1.49 \mathrm{~g} \mathrm{~cm}^{-3}$. The intrinsic density is different from the apparent density, calculated conventionally just by dividing the grammage by thickness (Fig. 2c). Here, the apparent density is affected by overestimation of the thickness because of the roughness of the surfaces, which is greater for lower grammage values, i.e., for thinner sheets. The greater roughness of BC sheets, caused by the lack of hemicellulose (Fig. 2a), results in higher discrepancy between apparent and intrinsic density values (Fig. 2c). Naturally, the density should not be affected by the grammage because thicker sheets are not expected to result in significantly altered inter-fibrillar distances within the sheet. For completeness, we note that the porosity of our networks calculated from the intrinsic density is around $7 \%$, assuming that the density of CNFs is $1.60 \mathrm{~g} \mathrm{~cm}^{-3}$, as revealed recently by Daicho et al. (Daicho et al. 2020).

Now, because the intrinsic density is independent of grammage, the tensile strength-when corrected for the sheet thickness - of the nanopapers should also be unaffected by the grammage. Nevertheless, Fig. 3a clearly demonstrates a trend with increasing tensile strength as the grammage is increased. For these and all subsequent tensile data reported, we overcome the systematic overestimate of thickness identified in our discussion of Fig. 2b by first calculating the specific strength (referred to as 'tensile index' in paper physics) by dividing the failure load per unit width by the grammage. We then multiply this value by the intrinsic density $\left(1.49 \mathrm{~g} \mathrm{~cm}^{-3}\right)$ to give the strength in $\mathrm{MPa}$. This weight-dependence phenomenon has been observed for conventional paper and ascribed to the more dominant influence of the surface in thinner papers: the fibers on the surface are bonded from one side only and their contribution to the network is relatively high with lower grammages, such that the tensile strength is correspondingly lower.(I'Anson et al. 2008) More unexpected is the difference between the two raw materials as BC nanopapers exhibit systematically lower tensile strength values than the NFC nanopapers - despite the obvious similarity in intrinsic density (Fig. 2b and c). 

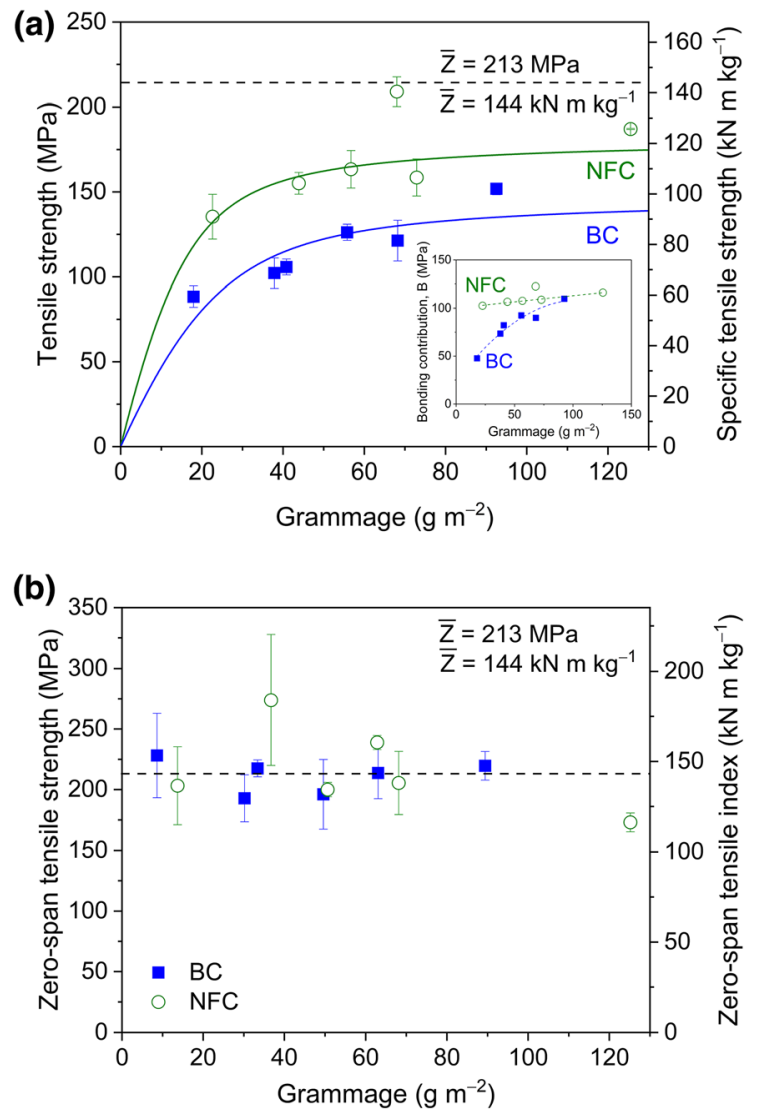

Fig. 3 a (Specific) tensile strength ( $\mathrm{MPa}$, specific: $\mathrm{kN} \mathrm{m} \mathrm{kg}^{-1}$ ) and $\mathbf{b}$ zero-span tensile strength (MPa) and index $\left(\mathrm{kN} \mathrm{m} \mathrm{kg}^{-1}\right)$ of bacterial- (BC, blue solid squares) and plant-derived nanofibrillated (NFC, green hollow circles) cellulose nanopapers with respect to grammage $\left(\mathrm{g} \mathrm{m}^{-2}\right)$. Mean values are marked with broken black lines. Inset in a: bonding contribution to tensile strength (B, MPa) with respect to grammage calculated using Eq. (1)

To gain better insight to the bonding differences between NFC and BC, we measured the zero-span tensile strength of the cellulose nanopapers (Fig. 3b). The zero-span test was developed for testing conventional paper, where the constituent fibers are sufficiently long that any fiber gripped by one pair of jaws is gripped by the opposing pair also.(Wathen et al. 2006) Naturally, it is difficult to define the length of BC fibrils, but scant reports on NFC have shown these to be of order 5 to $20 \mu \mathrm{m}$,(Chen et al. 2015) and thus shorter than the actual span between jaws. Importantly, we observe no significant or systematic change in the zero-span tensile index over the full range of grammages considered or between our two sources of cellulosic fibrils. In their study of the effect of span length on tensile index of CNF nanopapers, Varanasi et al.(Varanasi et al. 2012) showed that zero-span measurements closely approximate those obtained at incrementally small spans. As such, we proceed with the assumption that the zero-span test performed on cellulose nanopapers provides a good estimate of maximum strength that can be achieved from a network of the constituent nanofibrils instead of the strength of single CNF. For a self-bonded network of fibrils, this cannot exceed the strength of the constituent fibrils. On that basis, and for completeness, we use the theoretical treatment of Van den Akker et al.(Van den Akker et al. 1958) to estimate the tensile strength of individual fibrils $(\varphi)$ as:

$\varphi=\frac{8}{3} \rho_{c} Z$

where $\rho_{c}$ is the intrinsic density and $Z$ the measured zero span strength. For our fibrils, this yields an estimate of ca. $600 \mathrm{MPa}$, which is consistent with values reported for cellulosic fibers, including viscose.(Bledzki and Gassan 1999) However, the value is well below the lower end of what has been estimated for the strength of individual wood-based CNFs (2-6 GPa).(Saito et al. 2013) The discrepancy may arise in part from the coefficient $8 / 3$ which arises from the assumption that fibrils are randomly oriented in the plane of the network. This is qualitatively supported by SEM images (Fig. 4) but even moderate deviations from the assumption would yield substantially higher $\varphi$ values as the coefficient is 5 for uniformly random orientations in three dimensions.(Krenchell 1964).

When assessing how each factor contributes to the network strength, an important observation in Fig. 3b is that the zero-span strength appears to be independent of the biological origin of the CNF, which is sensible since the constituent fibers in the network consist of similar semi-crystalline cellulose fibrils. We will now employ the widely used, accessible and intuitively simple theory of Page,(Page 1969) upon which most other theories on densely bonded networks converge.(Jayaraman and Kortschot 1998) Given the low porosity of our networks, we can assume a high degree of inter-fibril contact and bonding, and indeed, Page equation has been successfully applied to CNF nanopapers recently.(Lindström 2017) In its simplest form, the equation describes the specific tensile strength, i.e., the tensile index $(T)$ as 
(a)

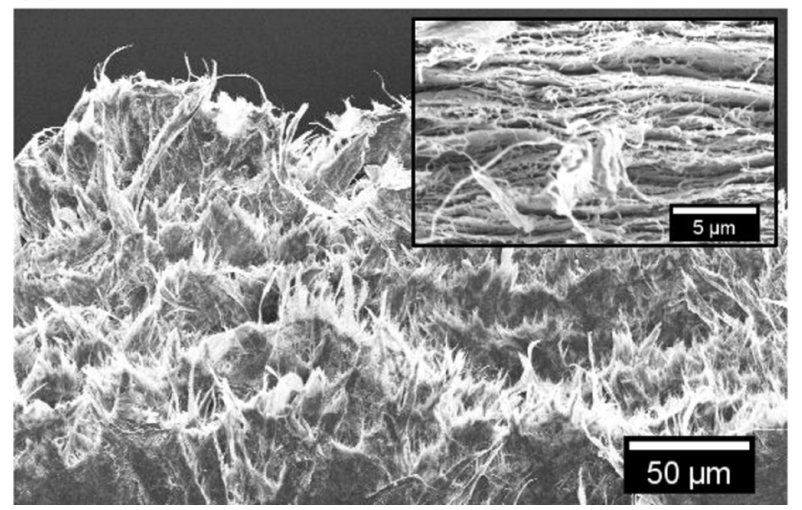

(b)

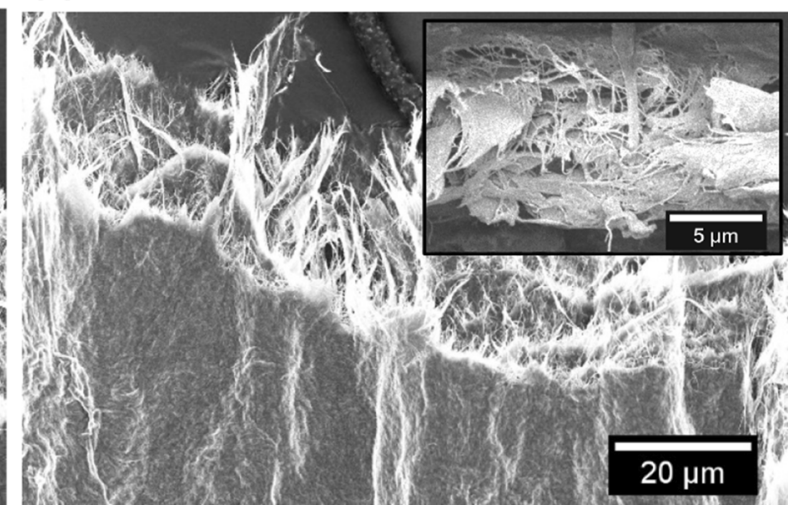

Fig. 4 SEM micrographs detailing the fracture surfaces of a high and $\mathbf{b}$ low grammage BC nanopapers. Insets provide higher magnification micrographs of the fracture cross section where the layered structure of the nanopapers is visible

$\frac{1}{T}=\frac{1}{Z}+\frac{1}{B}$

where $Z$ is the zero-span tensile index and $B$ the contribution of inter-fiber bonding. As $Z$ is independent of the biological source (Fig. 3b), the distinction in tensile strengths between $\mathrm{BC}$ and $\mathrm{CNF}$ nanopapers (Fig. 3a) can be ascribed to differences in $B$, i.e., bonding between CNFs. The only major dissimilarity between the two CNF grades is the presence of hemicelluloses in CNF. As stated earlier, amorphous, non-cellulosic polysaccharides in the form of, e.g., coiled xyloglucan have been shown to enhance the bond strength between cellulose microfibrils in the primary cell wall (Fig. 1, biomechanical hotspots).(Cosgrove 2014; Zhang et al. 2016) Although the major hemicellulose here (glucuronoxylan) is different from xyloglucan, it seems entirely reasonable to assume that these amorphous polysaccharides are at least partially responsible for the increased $B$ in NFC nanopapers (Fig. 3a inset). Indeed, it appears that the concept of biomechanical hotspots from plant physiology can - at least on some level-be transferred to CNF nanopapers with significant $(\sim 25 \%)$ strength increase (Fig. 3a). An analogous correlation has recently been observed with fungal chitin nanopapers where the coexistence of amorphous $\beta$-glucans with semi-crystalline chitin nanofibers has been shown to increase the tensile strength of the resulting nanopapers.(Nawawi et al. 2019) In addition, a positive effect of xylan on nanopaper strength has been semi-quantitatively demonstrated for NFC nanopapers previously.(Arola et al. 2013; Yang et al. 2020b) Recently, a similar correlative trend between hemicelluloses and tensile strength was reported for microfibrillated cellulose (MFC) papers in a technical study but the results are not quantitatively comparable with ours because of the high mineral content and coarser dimensions of MFC.(Taylor et al. 2020).

We emphasize that the effect of hemicelluloses on strength appears far greater than the distinction of CNF dimensions between NFC and BC-or indeed the fact that they have been prepared by very different means: NFC by mechanical disintegration of the cell wall and $\mathrm{BC}$ by bottom-up construction via microbial biosynthesis.

It is important to note that not all concepts derived for ordinary paper can necessarily be transferred directly to nanopapers by simply replacing "fibers" with "nanofibers". The CNFs are somewhat different from each other in dimensions: individual NFC used here (Lee et al. 2012) have approximately circular cross-sections with diameters around $50 \mathrm{~nm}$, which means that they consist of bundles of isolated microfibrils rather than individual wood-based microfibrils which are $\sim 3 \mathrm{~nm}$ in width (Saito et al. 2009). Individual BC (Fink et al. 1997), on the other hand, are ribbon-like with rectangular cross-sectional dimensions of approximately $100 \times 7 \mathrm{~nm}$ (Fig. 1). More importantly, however, in nanopapers, the CNFs form well-documented (Henriksson et al. 2008; Kulachenko et al. 2012; Li et al. 2016) lamellae which are visible in the cross-sectional scanning electron micrographs (Fig. 4). It is clear that the layers are 
thicker than the individual CNFs making up the layers and that higher grammages result in a higher number of layers (Fig. 4). Considering how stress transfer occurs in an ordinary fiber network, we can replace the fiber coverage (number of fibers at any one point) with layer coverage $n$ (number of layers at any one point), yielding a stress transfer function $(\Psi)$ as presented by I'Anson et al.:(I'Anson et al. 2008; I'Anson and Sampson 2007)

$\Psi=1-\frac{\gamma-\operatorname{Ei}(n)+\log (n)}{e^{n}-1}$

where $\gamma$ is the Euler-Mascheroni constant $(\sim 0.577)$ and $\mathrm{Ei}$ is the exponential integral function. The number of layers $(n)$ can be represented by ratio of the grammage of the sheet $(\beta)$ to the grammage of the constituent layers $\left(\beta_{L}\right)$. The tensile index $(T)$ is then derived from $\Psi$ by:

$T=K \Psi=K\left(1-\frac{\gamma-\operatorname{Ei}\left(\beta / \beta_{L}\right)+\log \left(\beta / \beta_{L}\right)}{e^{\beta / \beta_{L}}-1}\right)$.

Equation (4) can be fitted with $K$ and $\beta_{L}$ as the free parameters (curved line in Fig. 3a). Fitted values are provided in Table 1. Given the relatively sparse data set, the confidence intervals are inevitably rather large. Nevertheless, the values of 5-10 $\mathrm{g} \mathrm{m}^{-2}$, obtained for $\beta_{L}$, seem qualitatively consistent with the SEM images in Fig. 4 . The $\beta_{L}$ values are vital because they allow us to calculate the number of CNFs in a single lamella. From the dimensions of our nanofibrils, we calculate the grammage of a fibril to be $11 \mathrm{mg} \mathrm{m}^{-2}$ for BC and $61 \mathrm{mg} \mathrm{m}^{-2}$ for NFC, suggesting that our layers are of order 600 nanofibrils thick for $\mathrm{BC}$, and around 80 nanofibrils thick for NFC. SEM images of fracture surfaces of both BC and NFC in Figure S1 in the Supplementary Information qualitatively demonstrate this distinction. Further work is required to understand the source of these differences and their relation to underlying structural characteristics of the networks.

Table 1 Parameter estimates arising from least-squares fit of Eq. (4) to data in Fig. 3a

\begin{tabular}{lrll}
\hline & $\mathrm{K}\left(\mathrm{KN} \mathrm{m} \mathrm{Kg}^{-1}\right)$ & $\beta_{\mathrm{L}}\left(\mathrm{g} \mathrm{m}^{-2}\right)$ & $1^{2}$ \\
\hline BC & $99.1 \pm 22.5$ & $7.1 \pm 5.8$ & 0.823 \\
$\mathrm{NFC}$ & $122.1 \pm 16.7$ & $4.7 \pm 3.5$ & 0.869 \\
\hline
\end{tabular}

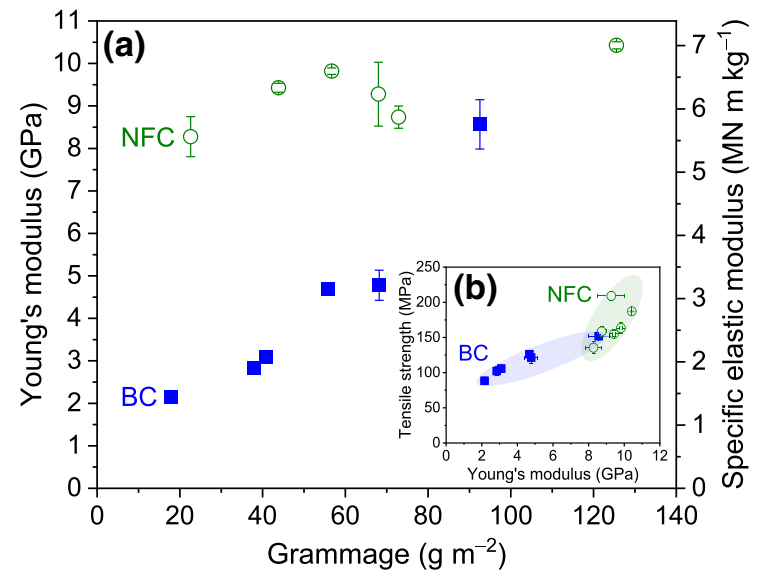

Fig. 5 a Young's modulus (GPa) and specific elastic modulus (MN m kg ${ }^{-1}$ ) of bacterial- (BC, blue solid squares) and plantderived nanofibrillated (NFC, green hollow circles) cellulose nanopapers with respect to grammage $\left(\mathrm{g} \mathrm{m}^{-2}\right)$. b Inset: tensile strength (MPa) with respect to Young's modulus (GPa)

As for the stiffness properties, Fig. 5a shows the Young's modulus plotted against grammage and we observe similar dependencies for both classes of nanopaper as for tensile strength. (The strain at break data have been compiled in Figure S2 in the Supplementary Information.) The data are combined in Fig. 5b, which shows the tensile strength plotted against the Young's modulus. It shows a contiguous data set for our two classes of nanopapers, with CNF nanopapers being stiffer and stronger than BC nanopapers, and the datum for the stiffest and strongest BC nanopaper among those for the CNF. We note that the tensile strengths and moduli obtained for our samples are of the same order of magnitude, but somewhat lower than the highest values that we are aware of for isotropic BC or NFC nanopapers (250-320 MPa).(Galland et al. 2015; Saito et al. 2009; Yang et al. 2020b; Österberg et al. 2013) We note, however, that according to the Page Eq. (2), specific tensile index cannot be higher than the measured zero span strength index. Therefore, at least for these particular CNFs, the tensile strength cannot significantly exceed $\sim 200 \mathrm{MPa}$.

\section{Conclusions}

In summary, our data and analyses show that the presence of hemicelluloses in CNF nanopapers has a decisive strengthening effect on nanopapers, so much 
so that the nanopapers from $\mathrm{BC}$ (without hemicelluloses) form a distinct dataset from the NFC nanopapers (with hemicelluloses). Hemicelluloses appear to influence the thickness and the grammage of the lamellae that make up the nanopaper structure strongly. These results are important when designing nanopaper structures for specific applications, e.g., in membrane technology, for use as $2 \mathrm{D}$ reinforcements in composites, or simply for strong, tough and optically transparent materials.

Acknowledgements KSK and AB acknowledge funding by the UK Engineering and Physical Sciences Research Council (EPSRC) (EP/K014676/1). KSK also acknowledges Academy of Finland (Project number 310943). EK is grateful for the support by the FinnCERES Materials Bioeconomy Ecosystem.

Funding Open access funding provided by Aalto University. KSK and AB acknowledge funding by the UK Engineering and Physical Sciences Research Council (EPSRC) (EP/K014676/1). KSK also acknowledges Academy of Finland (Project number 310943)

\section{Declarations}

Conflict of interest The authors declare that there is no conflict of interest.

Consent to participate All authors have consented to participate on the manuscript.

Consent for publication All authors have consented to the publication of the manuscript.

Open Access This article is licensed under a Creative Commons Attribution 4.0 International License, which permits use, sharing, adaptation, distribution and reproduction in any medium or format, as long as you give appropriate credit to the original author(s) and the source, provide a link to the Creative Commons licence, and indicate if changes were made. The images or other third party material in this article are included in the article's Creative Commons licence, unless indicated otherwise in a credit line to the material. If material is not included in the article's Creative Commons licence and your intended use is not permitted by statutory regulation or exceeds the permitted use, you will need to obtain permission directly from the copyright holder. To view a copy of this licence, visit http://creativecommons.org/licenses/by/4.0/.

\section{References}

Arola S, Malho JM, Laaksonen P, Lille M, Linder MB (2013) The role of hemicellulose in nanofibrillated cellulose networks. Soft Matter 9:1319-1326. https://doi.org/10. 1039/C2SM26932E

Barhoum A, Samyn P, Ohlund T, Dufresne A (2017) Review of recent research on flexible multifunctional nanopapers. Nanoscale 9:15181-15205. https://doi.org/10.1039/ c7nr04656a

Bledzki AK, Gassan J (1999) Composites reinforced with cellulose based fibres. Prog Polym Sci 24:221-274. https:// doi.org/10.1016/S0079-6700(98)00018-5

Bloch J-F, Engin M, Sampson WW (2019) Grammage dependence of paper thickness. Appita J 72:30-40

Chen W et al (2015) Revealing the structures of cellulose nanofiber bundles obtained by mechanical nanofibrillation via TEM observation. Carbohydr Polym 117:950-956. https://doi.org/10.1016/j.carbpol.2014.10.024

Cosgrove DJ (2014) Re-constructing our models of cellulose and primary cell wall assembly. Curr Opin Plant Biol 22:122-131. https://doi.org/10.1016/j.pbi.2014.11.001

Dai S et al (2018) Intrinsically ionic conductive cellulose nanopapers applied as all solid dielectrics for low voltage organic transistors. Nature Commun 9:2737. https://doi. org/10.1038/s41467-018-05155-y

Daicho K, Kobayashi K, Fujisawa S, Saito T (2020) Crystallinity-independent yet modification-dependent true density of nanocellulose. Biomacromol 21:939-945. https://doi.org/10.1021/acs.biomac.9b01584

Eronen P, Österberg M, Heikkinen S, Tenkanen M, Laine J (2011) Interactions of structurally different hemicelluloses with nanofibrillar cellulose. Carbohydr Polym 86:1281-1290. https://doi.org/10.1016/j.carbpol.2011.06. 031

Fang Z et al (2014) Novel nanostructured paper with ultrahigh transparency and ultrahigh haze for solar cells. Nano Lett 14:765-773. https://doi.org/10.1021/nl404101p

Fink H-P, Purz HJ, Bohn A, Kunze J (1997) Investigation of the supramolecular structure of never dried bacterial cellulose. Macromol Symp 120:207-217. https://doi.org/10.1002/ masy.19971200121

Galland S, Berthold F, Prakobna K, Berglund LA (2015) Holocellulose nanofibers of high molar mass and small diameter for high-strength nanopaper. Biomacromol 16:2427-2435. https://doi.org/10.1021/acs.biomac. 5 b00678

Henriksson M, Berglund LA, Isaksson P, Lindström T, Nishino $\mathrm{T}$ (2008) Cellulose nanopaper structures of high toughness. Biomacromol 9:1579-1585. https://doi.org/10.1021/ bm800038n

I'Anson SJ, Sampson WW (2007) Competing Weibull and stress-transfer influences on the specific tensile strength of a bonded fibrous network. Compos Sci Technol 67:1650-1658. https://doi.org/10.1016/j.compscitech. 2006.07.002

I'Anson SJ, Savani S, Sampson WW (2008) Density dependent influence of grammage on tensile properties of handsheets. J Pulp Pap Sci 34:182-189

Iwamoto S, Abe K, Yano H (2008) The effect of hemicelluloses on wood pulp nanofibrillation and nanofiber network characteristics. Biomacromol 9:1022-1026. https://doi. org/10.1021/bm701157n

Jarvis M (2018) Structure of native cellulose microfibrils, the starting point for nanocellulose manufacture. Phil Trans $r$ 
Soc A 376:20170045. https://doi.org/10.1098/rsta.2017. 0045

Jayaraman K, Kortschot MT (1998) Closed-form network models for the tensile strength of paper-a critical discussion. Nord Pulp Pap Res J 13:233-242. https://doi.org/ 10.3183/npprj-1998-13-03-p233-242

Kontturi E, Laaksonen P, Linder MB, Nonappa GAH, Rojas OJ, Ikkala O (2018) Advanced materials through assembly of nanocelluloses. Adv Mater 30:e1703779. https://doi.org/ 10.1002/adma.201703779

Krenchell H (1964) Fibre Reinforcement. Akademisk Forlag, Copenhagen

Kulachenko A, Denoyelle T, Galland S, Lindström SB (2012) Elastic properties of cellulose nanopaper. Cellulose 19:793-807. https://doi.org/10.1007/s10570-012-9685-5

Lee K-Y, Tammelin T, Schulfter K, Kiiskinen H, Samela J, Bismarck A (2012) High performance cellulose nanocomposites: comparing the reinforcing ability of bacterial cellulose and nanofibrillated cellulose. ACS Appl Mater Interfaces 4:4078-4086. https://doi.org/10.1021/ am300852a

Li Q et al (2016) Comparative study of the structure, mechanical and thermomechanical properties of cellulose nanopapers with different thickness. Cellulose 23:1375-1382. https:// doi.org/10.1007/s10570-016-0857-6

Lindström T (2017) Aspects on nanofibrillated cellulose (NFC) processing, rheology and NFC-film properties. Curr Opin Colloid Interface Sci 29:68-75. https://doi.org/10.1016/j. cocis.2017.02.005

Mautner A, Lee K-Y, Tammelin T, Mathew AP, Nedoma AJ, Li $\mathrm{K}$, Bismarck A (2015) Cellulose nanopapers as tight aqueous ultra-filtration membranes. React Funct Polym 86:209-214. https://doi.org/10.1016/j.reactfunctpolym. 2014.09.014

Nawawi W, Lee KY, Kontturi E, Murphy RJ, Bismarck A (2019) Chitin nanopaper from mushroom extract: natural composite of nanofibers and glucan from a single biobased source. ACS Sustain Chem Eng 7:6492-6496. https://doi. org/10.1021/acssuschemeng.9b00721

Nechyporchuk O, Belgacem MN, Bras J (2016) Production of cellulose nanofibrils: a review of recent advances. Ind Crops Prod 93:2-25. https://doi.org/10.1016/j.indcrop. 2016.02.016

Nobuta K et al (2016) Characterization of cellulose nanofiber sheets from different refining processes. Cellulose 23:403-414. https://doi.org/10.1007/s10570-015-0792-y

Österberg M, Vartiainen J, Lucenius J, Hippi U, Seppälä J, Serimaa R, Laine J (2013) A fast method to produce strong NFC films as a platform for barrier and functional materials. ACS Appl Mater Interfaces 5:4640-4647. https://doi. org/10.1021/am401046x

Page DH (1969) A theory of tensile strength of paper. Tappi J 52:674-681

Saito T, Hirota M, Tamura N, Kimura S, Fukuzumi H, Heux L, Isogai A (2009) Individualization of nano-sized plant cellulose fibrils by direct surface carboxylation using TEMPO catalyst under neutral conditions. Biomacromol 10:1992-1996. https://doi.org/10.1021/bm900414t

Saito T, Kuramae R, Wohlert J, Berglund LA, Isogai A (2013) An ultrastrong nanofibrillar biomaterial: the strength of single cellulose nanofibrils revealed via sonication-induced fragmentation. Biomacromol 14:248-253. https://doi.org/ $10.1021 / \mathrm{bm} 301674 \mathrm{e}$

Sun J et al (2018) Highly stretchable and ultrathin nanopaper composites for epidermal strain sensors. Nanotechnol 29:355304. https://doi.org/10.1088/1361-6528/aacc59

Taylor L, Phipps J, Blackburn S, Greenwood R, Skuse D (2020) Using fibre property measurements to predict the tensile index of microfibrillated cellulose nanopaper. Cellulose 27:6149-6162. https://doi.org/10.1007/s10570-02003226-2

Toivonen MS, Onelli OD, Jacucci G, Lovikka V, Rojas OJ, Ikkala O, Vignolini S (2018) Anomalous-diffusion-assisted brightness in white cellulose nanofibril membranes. Adv Mater 30:1704050. https://doi.org/10.1002/adma. 201704050

Van den Akker JA, Lathrop AJ, Voelker MH, Dearth LR (1958) Importance of fiber strength to sheet strength. Tappi J 41:416-425

Varanasi S, Chiam HH, Batchelor WJ (2012) Application and interpretation of zero and short-span testing on nanofibre sheet materials. Nord Pulp Pap Res J 27:343-351. https:// doi.org/10.3183/npprj-2012-27-02-p343-351

Wang $\mathrm{H}$ et al (2019a) Proton-conducting poly- $\gamma$-glutamic acid nanofiber embedded sulfonated poly(ether sulfone) for proton exchange membranes. ACS Appl Mater Interfaces 11:21865-21873. https://doi.org/10.1021/acsami.9b01200

Wang J, Tavakoli J, Tang Y (2019b) Bacterial cellulose production, properties and applications with different culture methods-A review. Carbohydr Polym 219:63-76. https:// doi.org/10.1016/j.carbpol.2019.05.008

Wathen R, Rosti J, Alava M, Salminen R, Joutsimo O (2006) Fiber strength and zero-span strength statistics-some considerations. Nord Pulp Pap Res J 21:193-201. https:// doi.org/10.3183/npprj-2006-21-02-p193-201

Yang X, Reid MS, Olsén P, Berglund LA (2020) Eco-friendly cellulose nanofibrils designed by nature: effects from preserving native state. ACS Nano 14:724-735. https://doi. org/10.1021/acsnano.9b07659

Yang B, Wang L, Zhang M, Luo J, Lu Z, Ding X (2020) Fabrication, applications, and prospects of aramid nanofiber. Adv Funct Mater 30(22):2000186. https://doi.org/10. 1002/adfm.202000186

Zeng F, Chen X, Xiao G, Li H, Xia S, Wang J (2020) A bioinspired ultratough multifunctional mica-based nanopaper with $3 \mathrm{~d}$ aramid nanofiber framework as an electrical insulating material. ACS Nano 14:611-619. https://doi.org/10.1021/acsnano.9b07192

Zhang T, Zheng Y, Cosgrove DJ (2016) Spatial organization of cellulose microfibrils and matrix polysaccharides in primary plant cell walls as imaged by multichannel atomic force microscopy. Plant J 85:179-192. https://doi.org/10. 1111/tpj.13102

Zhu $\mathrm{H}$ et al (2015) Anomalous scaling law of strength and toughness of cellulose nanopaper. PNAS 112:8971-8976. https://doi.org/10.1073/pnas.1502870112

Publisher's Note Springer Nature remains neutral with regard to jurisdictional claims in published maps and institutional affiliations. 